\title{
Prognostic Clinical and Laboratory Parameters in Children with primary Immune Thrombocytopenic Purpura
}

Prof.Dr.Randa Kamal Abdel Raouf Professor of Pediatrics Department of medical studies, Institute of postgraduate childhood studies Ain Shams University Dr.Ahmad Darwish Mohamad Lecturer Of Pediatrics, Faculty of Medicine- Mansoura University

Dr.Ziyad Mohamed Essam Eldin Tawhid Assistant professor of clinical pathology, Faculty of Medicine- Mansoura University Ain Shams University Amira Ahmed Nazim

\begin{abstract}
Immune thrombocytopenia (ITP) is an autoimmune disease characterized by a decreased platelet count (less than $100 \times 109 / \mathrm{L}$ ) due to destruction of antibody-sensitized platelets in the reticuloendothelial system (RES). ITP in children has a varied course and according to duration is distinguished as newly diagnosed ( $<3$ months), persistent (3-12), and chronic $(>12)$ types. Several studies have evaluated the prognostic factors for the progression of the disease. We aimed in this prospective study to identify prognostic parameters for the disease in 44 children in the period from October 2015 to November 2016 at Mansoura University Children Hospital (MUCH)\& Mansoura Health Insurance Hospital (MHIH) Information regarding age, gender, preceding infection, bleeding type, duration of symptoms and platelet count at diagnosis, treatment type, and antiglycoprotien antibodies was recorded. This study is designed to determine, the prognostic factors that could predict the disease course at diagnosi, estimate the presence of antibodies at disease onset and evaluate whether the antibody pattern at disease onset can predict the course of the disease, i.e. acute or chronic and evaluate treatment types and outcome in children with ITP From the studied cases 33 children had newly diagnosed and 11 chronic disease. Chronic ITP children had gradual initiation of the disease, higher initial platelet count compared to newly diagnosed group. Cutaneous bleeding was found in all cases. None of the children exhibited life threatening bleeding. Primary immune thrombocytopenic purpura (ITP) in childhood is usually a self-limiting disorder lasting a few weeks or months, but in approximately $25 \%$ of the children, the condition becomes chronic, defined as thrombocytopenia (platelet count less than $150 \times 109 / \mathrm{L}$ ) persisting for longer than 12 months from the onset of illness. In conclusion, even though ITP in children usually has a self- limited course, with rare serious bleeding complications, the chronic form of the disease is characterized by different predictive parameters, which can be used in clinical practice.
\end{abstract}

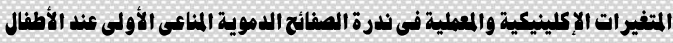

إن مرض قلة الصفائح الدوية المناعى الأولى هو اضطر اب المناعة الذاتية التى تتميز بانخفاض عدد الصفائح الدمية في غياب أسباب ثانوية أخرى. التبؤ من مسار المرض في وقت التشخيص يكن أن يكون أداة دفيدة فيما يتعلق بتخطيط العلاج، للحد هن مخاطر النزيف هع تجنب مضاعفات الأدوية كما أنه بساعد المرضى وأولياء

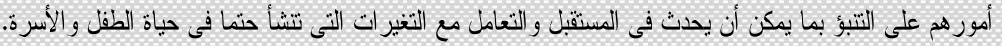

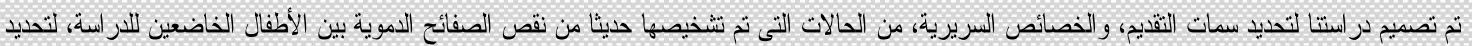
عوامل النذير التى يكن التبؤ من خلامها بمسار المرض فى التشخيص، لتحليل نشاط الأجسام المضادة أنتبليكوبروتين فى بداية الرض ونتيبي ما إذا كان نمط

الأجسام المضادة فى بداية المرض بحيث بكن التبؤ بمسار المرض، وتقييم أنو اع العلاج و النتائج في مرحلة الطفولة ديع نقص الصفائح الدموية.

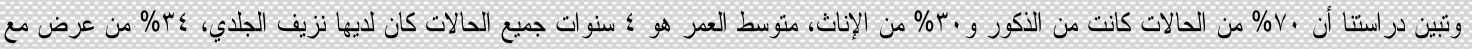

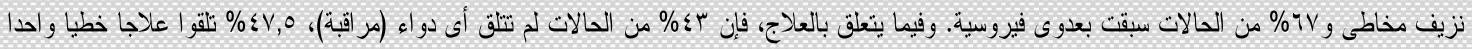

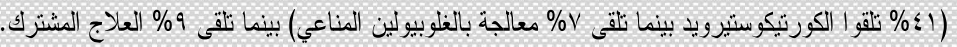

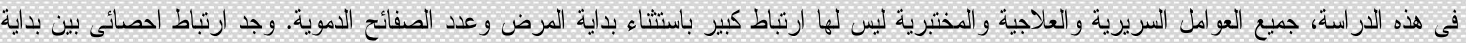

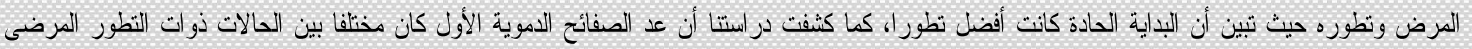

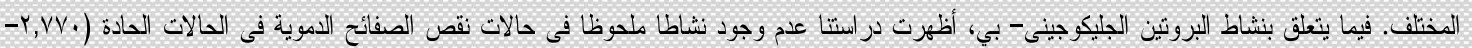

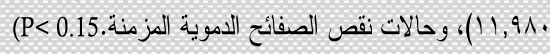




\section{Introduction:}

Primary immune thrombocytopenia (ITP) is an autoimmune disorder characterized by low platelet count $(<100 \times 109 / \mathrm{L})$ in the absence of other secondary causes. The disease is caused by increased platelet destruction by humoral or cellular immune mechanisms as well as inappropriate platelet production in the bone marrow. ${ }^{(1)}$ In children, it mainly occurs between 2 and 7 years of age and usually a viral infection of the respiratory or gastrointestinal tract precedes 2- 4 weeks earlier. At older ages, the precipitating factor of immune deregulation remains unknown. ${ }^{(2)}$

ITP is characterized by a variety of skin and mucous membrane bleeding manifestations such as petechiae, purpura, bruising, epistaxis, gingival bleeding, and menorrhagia. Severe intracranial bleeding is extremely rare, occurring in $0.5-1 \%$ of children when the platelet count drops below $10 \times 109 / \mathrm{L}^{(3)}$ According to the standardization of terminology, definitions and outcome criteria in ITP of adults and children published by Rodeghiero et.al., ITP in children is divided into newly diagnosed (duration $<3$ months, $50 \%$ of the cases), persistent (3- 12 months, $25 \%$ of the cases) and chronic (>12 months, $25 \%$ of the cases) type. The older time limit of 6 months to define chronicity is no longer in use. $^{(4)}$

Children who have no or mild bleeding can be managed with observation alone, regardless of platelet count. In cases requiring treatment, intravenous immunoglobulin (IVIG), anti- D immunoglobulin, or corticosteroids can be administered. ${ }^{(5)}$ When, despite repeated doses of first- line treatment, the disease becomes resistant and chronic lasting more than twelve months, other treatments should be applied. Recently, the use of the thrombopoietin receptor agonist eltrombopag has been approved in children older than one year with chronic ITP who have not responded to the administration of first- line drugs ${ }^{(6)}$ In refractory cases, other options are the use of rituximab, a monoclonal anti- CD20 chimeric antibody, or immunosuppressant drugs (e.g., cyclosporine, azathioprine, and mycophenolate mofetil). ${ }^{(7)}$ Splenectomy is an alternative choice with a significant risk of complications and is applied only in a few, very serious chronic cases. ${ }^{(8)}$

Reliable prediction of the course of the disease at time of diagnosis could be a useful tool regarding the planning of treatment, in order to minimize the risk of bleeding while avoiding drug complications. Also, it helps the patients and their parents to know what to expect in the future and to cope with the changes that inevitably arise in the life of the child and the family.

The predictors of the progression of the disease have been investigated in large, international studies with focus on the distinction between acute and chronic form using the time limit of 6 months from diagnosis. ${ }^{(9-11)}$ In recent studies, an effort has been made to determine the predictive parameters based on the new classification in which the time limit for chronic ITP is 12 months. ${ }^{(12-14)}$ A recent meta- analysis included all studies and showed that chronic ITP is mainly correlated with the female gender, older age at diagnosis, absence of recent infection, slow onset of symptoms, higher platelet count at diagnosis, the presence of antinuclear antibodies (ANA), and treatment with corticosteroids and IVIG. ${ }^{(13-15)}$

Since ITP is a heterogeneous disease, it is of great importance to confirm these ITP predictors, In Greece, one retrospective work has been published with a large number of children from Crete and it was mainly focused on the treatment and the response to it. ${ }^{(16)}$ The purpose of our study was to follow up selected newly diagnosed ITP cases in the period from October 2015 to November 2016 and asses them after 1year of diagnosis, in Mansoura University Children Hospital (MUCH) and Mansoura Health Insurance Hospital (MHIH) to point out the specific predictive characteristics related to the two categories of ITP (newly diagnosed and chronic)

\section{Hypothesis:}

This study hypothesizes that different clinical and laboratory parameters might be useful markers in determining the prognosis of children with ITP

\section{Aim Of The Study:}

To determine the prognostic factors that could predict the disease course at diagnosis

\section{Subjects And Methods:}

Forty- four children with newly diagnosed ITP from those attented MUCH\& MHIH, from October 2015 to November 2016, were prospectively studied. The demographic, clinical, and laboratory data of patients were recorded. The study was approved by the scientific ethical committee of the institute of postgraduate childhood studies, Ain Shams University. The diagnosis of primary ITP was set in children with isolated thrombocytopenia $(<100 \times 109 / \mathrm{L})$ in the absence of other causes that may be associated with thrombocytopenia. Children with secondary thrombocytopenia due to systemic disease or medications, patients with incomplete clinical data, or patients that discontinued monitoring in our department were excluded from the study. All children had a minimum of 1 year of follow- up

Demographic data were collected such as name, date of birth, age, sex, and place of residence. Medical and family history were recorded. The clinical data were collected at diagnosis such as onset, season, preceding viral infection and type of bleeding. Laboratory findings such as $\mathrm{CBC}$ (using coulter analyzer), antiglycoprotien antibodies using ELISA, BMA in atypical cases were recorded. We also recorded the type of treatment and the response.

Newly diagnosed ITP was defined as the presence of thrombocytopenia for $<3$ months after diagnosis, persistent for (3- 12) months, and chronic ITP for $>12$ months. The onset of symptoms was defined as abrupt when bleeding symptoms lasted for less than two weeks before seeking assistance or as gradual when they lasted more than two weeks before the medical assessment. A history of recent infection was defined as a recorded infection of the upper respiratory or gastrointestinal tract over four weeks before the diagnosis of ITP.

The statistical analysis was done using the SPSS 17.0 statistical 
program. Numerical data and categorical variables were analyzed by the Mann- Whitney $(\mathrm{U})$ or- tests and the chi- square test, respectively. The odds ratio (OR) and $95 \%$ confidence interval $(\mathrm{CI})$ were used to determine the increased relative risk. Values less than 0.05 were considered statistically significant.

\section{Results:}

A total of 44 children diagnosed with ITP were followed during the study period. 33 (75\%) children had newly diagnosed form and $11(25 \%)$ children have chronic form Figure (1). The characteristics of the newly diagnosed group were compared with the chronic ITP group; the findings are summarized in Table (1)\& (2).

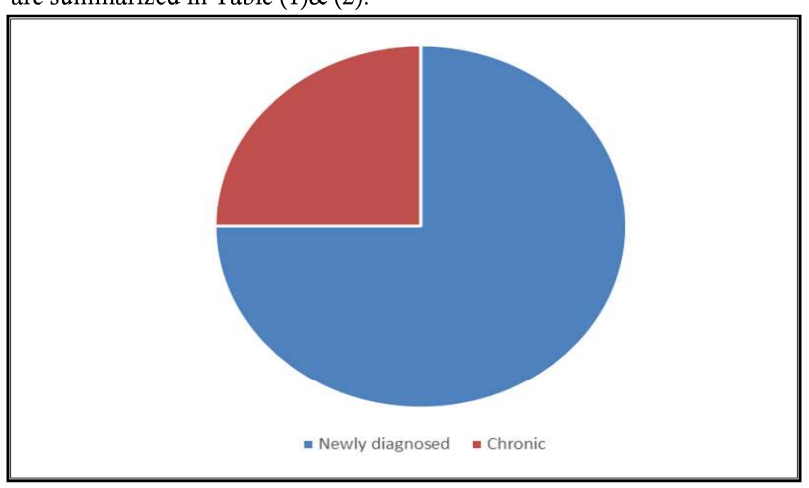

Figure (1) Number of children with newly diagnosed and chronic ITP Table (1) Comparison between demographic data of newly diagnosed \& chronic patients

\begin{tabular}{|c|c|c|c|c|c|c||}
\hline \multirow{2}{*}{} & \multicolumn{4}{|c||}{ Course } & \multirow{2}{*}{ P } \\
\cline { 2 - 6 } & \multicolumn{3}{|c|}{ Newly Diagnosed } & \multicolumn{2}{c|}{ Chronic } & \\
\hline \multirow{2}{*}{ Age In Years } & 4.00 & $1.58-12.00$ & 6.00 & $3.00-8.00$ & \multirow{2}{*}{0.5} \\
\hline \multirow{2}{*}{ Sex } & Male & 24 & $72.7 \%$ & 7 & $63.6 \%$ & \multirow{2}{*}{0.56} \\
\cline { 2 - 6 } & Female & 9 & $27.3 \%$ & 4 & $36.4 \%$ & \\
\hline \multirow{2}{*}{ Residence } & rural & 27 & $81.8 \%$ & 10 & $90.9 \%$ & \multirow{2}{*}{0.47} \\
\cline { 2 - 6 } & urban & 6 & $18.2 \%$ & 1 & $9.1 \%$ & \\
\hline
\end{tabular}

P: Probability, *: significance $<0.05 \mathrm{p}$

Table (1) Shows no statistically significant correlation between demographic data of both groups and the course of the disease Data expressed as median (IQR) or as frequency (Number- percent)

Test used: Mann- Whitney test for data expressed as median (IQR) and Chi- square for data expressed as frequency

Table (2) comparing the clinical findings of patients of both groups

\begin{tabular}{|c|c|c|c|c|c|c|}
\hline & & \multicolumn{4}{|c|}{ Course } & \multirow{3}{*}{$P$} \\
\hline & & \multicolumn{2}{|c|}{ Newly Diagnosed } & \multicolumn{2}{|c|}{ Chronic } & \\
\hline & & $\mathrm{N}$ & $\%$ & $\mathrm{~N}$ & $\%$ & \\
\hline \multirow{4}{*}{ Season } & Winter & 16 & $48.5 \%$ & 6 & $54.5 \%$ & \multirow{4}{*}{0.78} \\
\hline & Fall & 13 & $39.4 \%$ & 3 & $27.3 \%$ & \\
\hline & Spring & 3 & $9.1 \%$ & 1 & $9.1 \%$ & \\
\hline & Summer & 1 & $3.0 \%$ & 1 & $9.1 \%$ & \\
\hline \multirow{2}{*}{ Onset } & Sudden & 32 & $97.0 \%$ & 8 & $72.7 \%$ & \multirow{2}{*}{$0.015^{*}$} \\
\hline & Gradual & 1 & $3.0 \%$ & 3 & $27.3 \%$ & \\
\hline \multirow{2}{*}{$\begin{array}{c}\text { Preceding Viral } \\
\text { Infection }\end{array}$} & $\mathrm{N}$ & 11 & $33.3 \%$ & 4 & $36.4 \%$ & \multirow{2}{*}{0.85} \\
\hline & $\mathrm{P}$ & 22 & $66.7 \%$ & 7 & $63.6 \%$ & \\
\hline \multirow{2}{*}{$\begin{array}{c}\text { Cutaneous } \\
\text { Bleeding }\end{array}$} & $\mathrm{N}$ & 0 & $0.0 \%$ & 0 & $0.0 \%$ & \multirow{2}{*}{ - } \\
\hline & $\mathrm{P}$ & 33 & $100.0 \%$ & 11 & $100.0 \%$ & \\
\hline \multirow{2}{*}{$\begin{array}{l}\text { Mucosal } \\
\text { Bleeding }\end{array}$} & $\mathrm{N}$ & 20 & $60.6 \%$ & 9 & $81.8 \%$ & \multirow{2}{*}{0.19} \\
\hline & $\mathrm{P}$ & 13 & $39.4 \%$ & 2 & $18.2 \%$ & \\
\hline
\end{tabular}

P: Probability, ${ }^{*}$ : significance $<0.05$, Test used Chi- square $\mathrm{N}=\mathrm{n}$ umber $\%=$ frequency

Table (2) comparing the clinical findings of newly diagnosed and chronic cases with no significant difference between them except Sudden onset has statistically significant correlation with the course of the disease $(\mathrm{p}=0.015)$

The age range of the patients varied from $\geq 3$ months $\& \leq 18$ years with a median value of 4.33 years. Regarding the children with newly diagnosed disease, the median age was 4 (range 1.58-12). In the chronic disease group, the median age was 6 (range 3-8). The comparison between the two groups revealed no statistically significant result, meaning that the age cannot predict the course of the disease Figure (2)

Of the 44 children, 13 were girls (30\%) and 31 boys (70\%). 24 were boys (73\%) and 9 were girls (27\%) In the newly diagnosed group, 7 (64\%) children were boys, while $4(36 \%)$ children were girls in the chronic disease group, with non- statistically significant difference

Recent infection history was recorded in $22(67 \%)$ children with newly diagnosed disease and in 7 (63\%) from the chronic ITP group, which was not a statistically significant result $(p=0.85)$ Figure (3).

The median platelet count at diagnosis was $12.35 \times 109 / \mathrm{L}$ (range 9. 22 ) in newly diagnosed type and $28 \times 109 / \mathrm{L}$ (range 13- 60) in chronic ITP. Platelet count in newly diagnosed cases was lower than chronic cases the comparison between the two groups revealed statistically significant result $\left(p=0.049^{*}\right)$, meaning that the initial platelet count can predict the course of the disease, Figure (4).

Mucosal bleeding was observed in 15 of 44 patients (34\%). In the newly diagnosed, 13 of 33 children (39\%) had mucosal bleeding, while the same number in chronic ITP group was $2 / 11$ (18\%), a nonsignificant result Figure (5). None of our patients developed intracranial (ICH) at diagnosis or during follow up period.

Concerning the onset of symptoms, the disease occurred abruptly in 32 of $33(97 \%)$ of the cases with newly diagnosed form. In contrast, 8 of 11 (73\%) children with chronic disease had abrupt onset, a statistically significant difference $(p=0.015)$ Figure (6).

Regarding median of antiglycoprotien antibodies in newly diagnosed cases was 4 (range 2.7-11.9) On the contrary, chronic ITP children had a median of 2.6 (range $1.9-6.5$ ) with no statistically significant result $(p=$ $0.15)$ Figure (7).

In newly diagnosed cases, 16 of 33 children (48.5\%) received no treatment another 16 of 33 children received corticosteroids or IVIG, only 1of 33 received combined therapy. Table (3)\& (4).

Among the potential predicting factors for developing chronic ITP at diagnosis, the most significant predictors were found to be the gradual onset of the disease \& initial low platelet count, by using stepwise logistic regression the course of the disease is dependent on the initial platelet count only. 


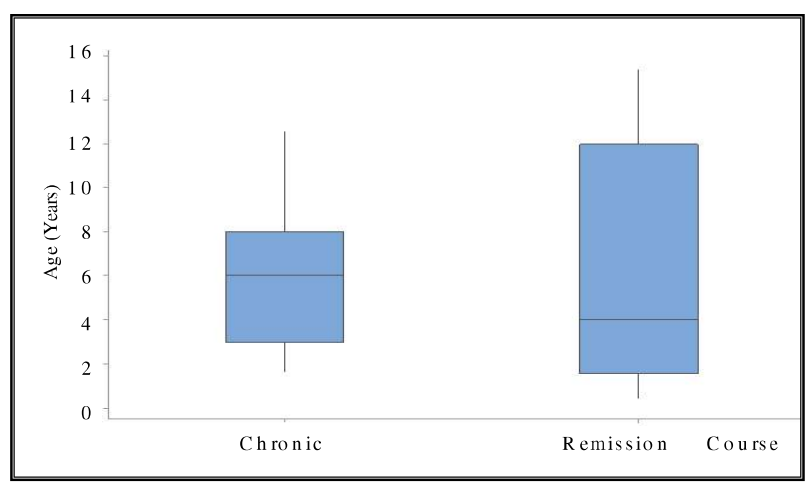

Figure (2) shows a box plot comparing the age of the patient in the two different groups.

The 75th and 25th percentiles of the data limit the boxes. The middle lines represent the median

There is no statistically significant correlation between the age of the patients and the course of the disease

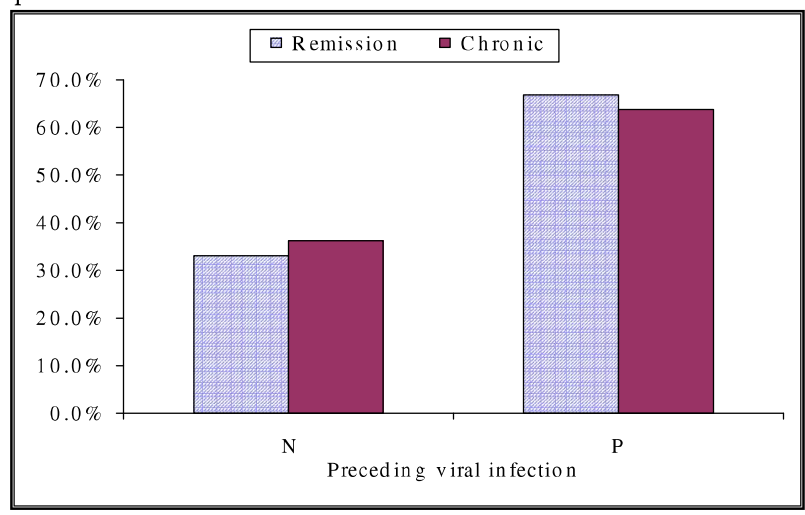

Figure (3) linear bars comparing the presence or absence of preceding viral infection in both groups with no significant correlation between the presence or absence of preceding viral infection and the course of the disease $(\mathrm{p}=0.85)$.

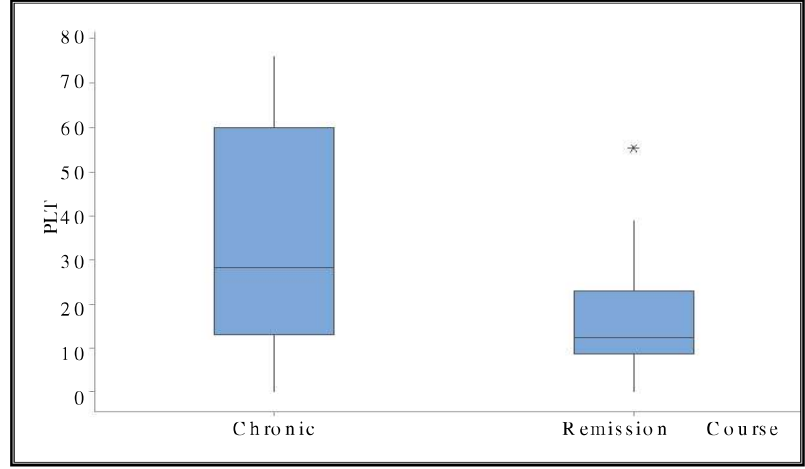

Figure (4) shows a box plot comparing the platelet count in both patient groups. The boxes are limited by the 75 th and 25 th percentiles of the data. The middle lines represent the median. There was statistically significant correlation between the platelet count and the course of the disease $(p=0.049 *)$.

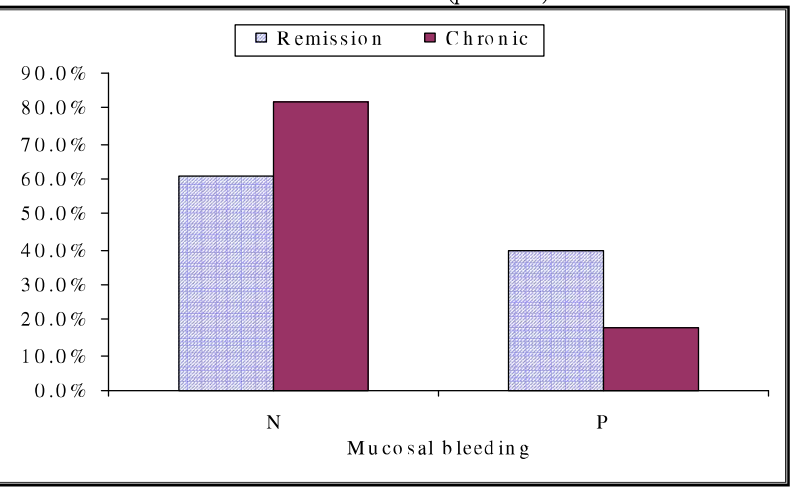

Figure (5) linear bars comparing the presence or absence of mucosal bleeding in both groups with no significant difference between them $(p=0.19)$.

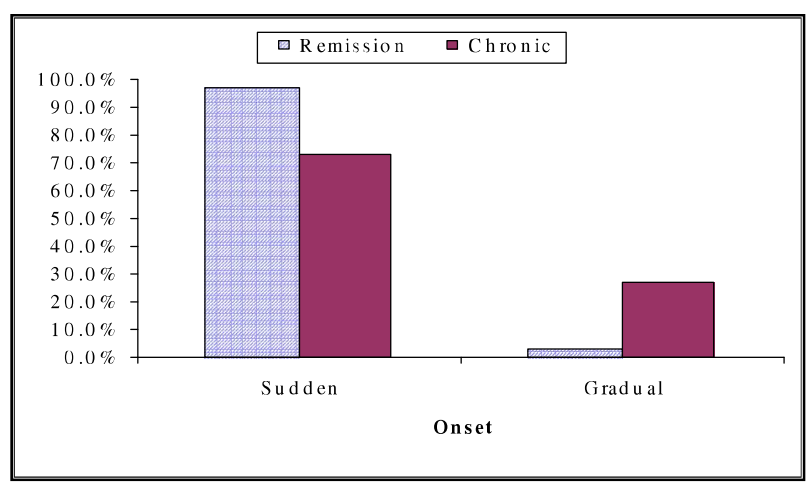

Figure (6) linear bars comparing the onset of the disease in both groups with significant difference between them $(p=0.015)$.

Table (3) Descriptive data of different lines of treatment had been taken by the studied

\begin{tabular}{|c|l|c|c|}
\hline \multicolumn{2}{|c|}{ Treatment } & N & $\%$ \\
\hline \multirow{4}{*}{ TTT } & Conservative (No Medication) & 19 & $43.2 \%$ \\
\cline { 2 - 4 } & Corticosteroid & 18 & $40.9 \%$ \\
\cline { 2 - 4 } & IVIG & 3 & $6.8 \%$ \\
\cline { 2 - 4 } & Corticosteroid + Azathioprine & 2 & $4.5 \%$ \\
\cline { 2 - 4 } & Corticosteroid + IVIG & 1 & $2.3 \%$ \\
\cline { 2 - 5 } & Corticosteroid +Ivig+ Azathioprine & 1 & $2.3 \%$ \\
\hline
\end{tabular}

Table (4) comparing different lines of treatment had been taken by the patient and the

\begin{tabular}{|c|c|c|c|c|c|c|}
\hline & & \multicolumn{4}{|c|}{ Course } & \multirow{3}{*}{$\mathrm{P}$} \\
\hline & & \multicolumn{2}{|c|}{ Newly Diagnosed } & \multicolumn{2}{|c|}{ Chronic } & \\
\hline & & No & $\%$ & No & $\%$ & \\
\hline \multirow{3}{*}{ TTT } & None & 16 & $48.5 \%$ & 3 & $27.3 \%$ & 0.3 \\
\hline & Single & 16 & $48.5 \%$ & 5 & $45.5 \%$ & 1.00 \\
\hline & Combined & 1 & $3.0 \%$ & 3 & $27.3 \%$ & $0.04^{*}$ \\
\hline
\end{tabular}

P: Probability *: significance $<0.05$ Test used: Chi- square

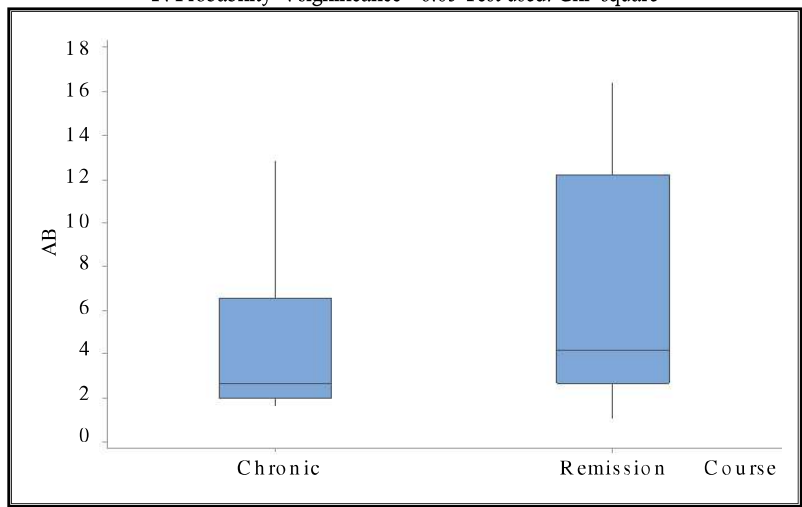

Figure (7) shows a box plot comparing the antiglycoprotien antibodies in both patient groups. The boxes are limited by the 75 th and 25 th percentiles of the data. The middle lines represent the median. There is no statistically significant difference between both groups $(p=0.15)$

\section{Discussion:}

The present study investigated the parameters at diagnosis that distinguish the newly diagnosed from chronic ITP. According to the results, chronic ITP children are more likely to be of gradual onset, higher initial platelet counts and treated by combined therapy.

The age of the patients at diagnosis has been investigated as a predictor factor in several studies with large number of patients. The investigators of the Intercontinental Childhood ITP Study Group observed that chronic ITP was more frequently found in children above 10 years of age $(47.3 \%)$ rather than infants $(23.1 \%){ }^{(9)}$ In another large, multicenter study, it was noticed that children at the age of 10 years were at higher risk 
for developing chronic ITP than at the age of 2 years. ${ }^{(10)}$ In our study, we observed no statistically difference. Also, in our study, the two forms of the disease showed a similar incidence in both genders, a finding that is in accordance with previous studies. ${ }^{(17)}$

Preceding infection has been reported as a frequent finding in childhood ITP. In a large single center study, history of recent infection at diagnosis was reported in $56 \%$ of newly diagnosed cases. In contrast, $77 \%$ of patients with chronic disease had no history of preceding infection. ${ }^{(18)}$ In a population- based, cohort study of the predictors of chronic ITP, it was found that patients with a history of recent infection at diagnosis were less likely to develop chronic ITP than patients without a relevant history (relative risk 0.44). ${ }^{(10)}$ The most common viral agents that cause infectious diseases in childhood can potentially cause a transient immunological deregulation that leads to the production of antiplatelet antibodies and ITP with acute and self- limiting characteristics. A possible explanation for this causative linkage is the theory of molecular mimicry, which suggests that similarities between pathogen antigens and platelets act as a mechanism for the transient production of antiplatelet antibodies from the patient's lymphocytes. ${ }^{(19)}$ Exceptions are other infectious agents, such as cytomegalovirus, which may have more chronic and persistent influence on the immune system. ${ }^{(20)}$ In our study, we observed no statistically difference

The duration of the bleeding symptoms before diagnosis has been reported to determine the course of the disease. Large, retrospective studies emphasized that the most important prognostic factor of chronic ITP is the slow onset of bleeding symptoms. ${ }^{(18,21)}$ In our study, the results were similar and highlight the importance of the duration of symptoms before diagnosis as an important prognostic indicator for disease progression

Due to the immunological background of ITP, testing and monitoring for antiglycoprotien antibodies were done. ${ }^{(22.23)}$

Platelet count at diagnosis is an important laboratory predictor of the course of ITP. In the study of Lowe and Buchanan, the mean platelet count at diagnosis was $21 \times 109 / \mathrm{L}$ in chronic cases and $5.5 \times 109 / \mathrm{L}$ in newly diagnosed ITP. ${ }^{(22)}$ Additionally, Glanz et.al. reported that a high number of platelets at diagnosis ( $>20 \times 109 / \mathrm{L})$ combined with the age above 10 years increased the risk of chronic disease fourfold, compared to younger patients with low platelets. Moreover, at the platelet threshold above $30 \times 109 / \mathrm{L}$, the same risk was eleven times greater ${ }^{(10)}$ In agreement with these data, our study showed that most of patients with chronic disease had high initial platelets count above 10× 109/ L at diagnosis.

Mucosal bleeding is an important complication of ITP and when it is serious, treatment is required to increase the platelet number. However, several studies suggest that, despite its increased incidence and severity, mucosal bleeding is associated with a short disease duration. Elalfy et.al. showed that a history of mucosal bleeding at diagnosis is most often associated with acute disease. Specifically, from 224 children with acute disease, $31 \%$ had bleeding from mucous membranes, while in the group of
120 children with chronic disease the same proportion was only $6.5 \%{ }^{(18)}$ Similar results were published in earlier studies. ${ }^{(10)}$ in our study no statistically difference between the absence or presence of mucosal bleeding and the course of the disease.

The administration of IVIG or corticosteroids, when needed, is a welldocumented treatment option in ITP. Data from the Intercontinental Childhood ITP Study Group showed that children with the acute type of the disease had received more often IVIG than the chronic ITP children $(32.3 \%$ versus $23.8 \%) .{ }^{(24)} \mathrm{A}$ recent meta- analysis provided similar findings regarding the use of IVIG and corticosteroids and concluded that they may prevent the chronic progression of the disease.$^{(15)}$ in our study half of the newly diagnosed disease received no treatment and the other half received corticosteroid, only three cases received IVIG because of low resources, so we can not compare the use of corticosteroid with the use of IVIG. Although the immunomodulatory action of IVIG is not fully elucidated, it has been shown to affect both humoral and cellular immune pathways. In ITP patients, IVIG blocks the activation of Fc- receptors in macrophages of the reticuloendothelial system ${ }^{(25,26)}$ Since ITP is considered a heterogeneous disease, IVIG may have various effects in different patients, thus explaining why not all patients respond the same way to the treatment.

In conclusion, this prospective study determined the prognostic characteristics of ITP in children. It is confirmed that primary ITP in children is a nonthreatening and self- limited disease, usually lasting less than one year, and chronic form has different prognostic parameters. The use of these parameters can early distinguish children who are expected to have short and uneventful disease duration, in order to minimize their exposure to pharmaceutical interventions. In different case, physicians should be prepared for different diagnostic evaluation and treatment decision options for chronic disease.

\section{References:}

1. Abadi U., Dolberg O. Y., Ellis M. H, 2015. Immune thrombocytopenia: recent progress in pathophysiology and treatment. Clinical and Applied Thrombosis/ Hemostasis. 21(5): 397- 404. doi: 10.1177/ 1076029614526639. (PubMed) (Cross Ref)

2. Fogarty P. F., Segal J. B, 2007. The epidemiology of immune thrombocytopenic purpura. Current Opinion in Hematology. 14(5): 515- 519. doi: 10.1097/ MOH. 0b013e3282ab98c7. PubMed Cross Ref

3. Arnold D. M, 2015. Bleeding complications in immune thrombocytopenia. International Journal of Hematology. (1): 237242. doi: 10.1182/asheducation- 2015.1.237. (PubMed) (Cross Ref)

4. Rodeghiero F., Stasi R., Gernsheimer T., et.al, 2009. Standardization of terminology, definitions and outcome criteria in immune thrombocytopenic purpura of adults and children: report from an international working group. Blood. 113(11): 2386- 2393. doi: 10.1182/ blood- 2008- 07- 162503. (PubMed) (Cross Ref)

5. Provan D., Stasi R., Newland A. C., et.al, 2010. International consensus report on the investigation and management of primary 
immune thrombocytopenia. Blood. 115(2): 168- 186. doi: 10.1182/ blood- 2009- 06- 225565. (PubMed) (Cross Ref)

6. Burness C. B., Keating G. M., Garnock- Jones K. P, 2016. Eltrombopag: A Review in Paediatric Chronic Immune Thrombocytopenia. Drugs. 76(8): 869- 878. doi: 10.1007/s40265- 0160581- 4. (PubMed)(Cross Ref)

7. Liang Y., Zhang L., Gao J., Hu D., Ai Y, 2012. Rituximab for children with immune thrombocytopenia: A systematic review. PLoS 1; 7(5) doi: 10.1371/ Journal. Pone. 0036698. e36698 (PMC free article)(PubMed) (Cross Ref)

8. Imbach P, 2003. Refractory Idiopathic Immune Thrombocytopenic Purpura in Children: Current and Future Treatment Options. Pediatric Drugs. 5(12): 795- 801. doi: 10.2165/ 00148581- 200305120 00003. (PubMed) (Cross Ref)

9. Kühne T., Buchanan G. R., Zimmerman S., et.al, 2003. A prospective comparative study of 2540 infants and children with newly diagnosed idiopathic thrombocytopenic purpura (ITP) from the intercontinental childhood ITP study group. Journal of Pediatrics. 143(5): 605- 608 . doi: 10.1067/S0022- 3476(03)00535- 3. (PubMed) (Cross Ref)

10. Glanz J., France E., Xu S., Hayes T., Hambidge S, 2008. A population- based, multisite cohort study of the predictors of chronic idiopathic thrombocytopenic purpura in children. Pediatrics; 121(3): e506- e512. doi: 10.1542/ peds. 2007- 1129. (PubMed) (Cross Ref)

11. Robb L. G., Tiedeman K, 1990. Idiopathic thrombocytopenic purpura: Predictors of chronic disease. Archives of Disease in Childhood. 65(5): 502- 506. doi: 10.1136/adc. 65.5.502. (PMC free article) (PubMed)(Cross Ref)

12. Revel- Vilk S., Yacobovich J., Frank S., et.al, 2013. Age and duration of bleeding symptoms at diagnosis best predict resolution of childhood immune thrombocytopenia at 3, 6, and 12 months. Journal of Pediatrics. 163(5): 1335- e2. doi: 10.1016/j. jpeds. 2013.06.018. (PubMed) (Cross Ref)

13. Edslev P. W., Rosthøj S., Treutiger I., Rajantie J., Zeller B., Jonsson O. G, 2007. A clinical score predicting a brief and uneventful course of newly diagnosed idiopathic trombocytopenic purpura in children. British Journal of Haematology. 138(4): 513- 516. doi: 10.1111/j. 1365- 2141.2007.06682. x. (PubMed)(Cross Ref)

14. Bennett C. M., Neunert C., Grace R. F., et.al, 2017. Predictors of remission in children with newly diagnosed immune thrombocytopenia: data from the intercontinental cooperative itp study group registry ii participants. Pediatric Blood\& Cancer. doi: 10.1002/ pbc. 26736. (PubMed) (Cross Ref)

15. Heitink- Pollé K. M. J., Nijsten J., Boonacker C. W. B., De Haas M., Bruin M. C. A, 2014. Clinical and laboratory predictors of chronic immune thrombocytopenia in children: A systematic review and meta- analysis. Blood; 124(22): 3295- 3307. doi: 10. 1182/ Blood2014- 04- 570127. (PubMed) (Cross Ref)

16. Stiakaki E., Perdikogianni C., Thomou C., et.al, 2012. Idiopathic thrombocytopenic purpura in childhood: Twenty years of experience in a single center. Pediatrics International. 54 (4): 524- 527. doi: 10.1111/j. 1442- 200X. 2012.03606. x. (PubMed) (Cross Ref)

17. Imbach P., Kühne T., Müller D., et.al, 2006. Childhood ITP: 12 Months follow- up data from the prospective registry $\mathrm{I}$ of the Intercontinental Childhood ITP Study Group (ICIS) Pediatric Blood\& Cancer; 46 (3): 351- 356. doi: 10.1002/ pbc. 20453. (PubMed) (Cross Ref)

18. Elalfy M., Farid S., Maksoud A. A, 2010. Predictors of chronic idiopathic thrombocytopenic purpura. Pediatric Blood\& Cancer. 54(7): 959- 962. doi: 10.1002/pbc. 22481. (PubMed) (Cross Ref)

19. Rand M. L., Wright J. F, 1998. Virus- associated Idiopathic Thrombocytopenic Purpura. Transfusion Science. 19(3): 253- 259. doi: 10.1016/S0955- 3886(98)00039- 3. (PubMed) (Cross Ref)

20. Shimanovsky A., Patel D., Wasser J, 2016. Refractory immune thrombocytopenic purpura and cytomegalovirus infection: A call for a change in the current guidelines. Mediterranean Journal of Hematology and Infectious Diseases. 8(1) doi: 10.4084/mjhid. 2016.010. e2016010 (PMC free article) (PubMed) (Cross Ref)

21. Zeller B., Rajantie J., Hedlund- Treutiger I., et.al, 2005. Childhood idiopathic thrombocytopenic purpura in the Nordic countries: Epidemiology and predictors of chronic disease. Acta Paediatrica; 94 (2): 178- 184. doi: 10. 1080/ 080352504 10025294. (PubMed) (Cross Ref)

22. Lowe E. J., Buchanan G. R, 2002. Idiopathic thrombocytopenic purpura diagnosed during the second decade of life. Journal of Pediatrics; 141(2): 253- 258. doi: 10.1067/ mpd. 2002. 125909. (PubMed) (Cross Ref)

23. Zimmerman S. A., Ware R. E, 1997. Clinical significance of the antinuclear antibody test in selected children with idiopathic thrombocytopenic purpura. Journal of Pediatric Hematology/ Oncology; 19 (4): 297- 303. doi: 10.1097/ 00043426- 19970700000006. (PubMed) (Cross Ref)

24. Tamminga R., Berchtold W., Bruin M., Buchanan G. R., Kühne T, 2009. Possible lower rate of chronic ITP after IVIG for acute childhood ITP an analysis from registry $i$ of the Intercontinental Cooperative ITP Study Group (ICIS) British Journal of Haematology; 146(2): 180- 184. doi: 10.1111/j. 1365- 2141. 2009.07743. x. (PubMed) (Cross Ref)

25. Samuelsson A., Towers T. L., Ravetch J. V, 2001. Anti- inflammatory activity of IVIG mediated through the inhibitory Fc receptor. Science; 291(5503): 484- 486. doi: 10.1126/ Science. 291.5503.484. (PubMed)(Cross Ref)

26. Crow A. R., Song S., Freedman J., et.al, 2003. IVIG- mediated amelioration of murine ITP via Fc $\gamma$ RIIB is independent of SHIP1, SHP- 1, and Btk activity. Blood; 102(2): 558- 560. doi: 10.1182/ blood- 2003- 01- 0023. (PubMed) (Cross Ref). 